\title{
Article
}

\section{Arabidopsis SUMO E3 Ligase SIZ1 Interacts with HDA6 and Negatively Regulates HDA6 Function during Flowering}

\author{
Sujuan Gao ${ }^{1,+}{ }^{,}$Xueqin Zeng ${ }^{2,+}$, Jianhao Wang ${ }^{3}$, Yingchao Xu ${ }^{4}$, Chunwei Yu ${ }^{5} \mathbb{D}$, Yishui Huang ${ }^{4}$, Feng Wang ${ }^{2}$, \\ Keqiang $W u$ 5,*(D) and Songguang Yang ${ }^{4,6, *(D)}$
}

1 Key Laboratory of Green Processing and Intelligent Manufacturing of Lingnan Specialty Food, College of Light Industry and Food Science, Zhongkai University of Agriculture and Engineering, Ministry of Agriculture, Guangzhou 510225, China; gaoshj@126.com

2 Guangdong Provincial Key Laboratory of New Technology in Rice Breeding, Rice Research Institute, Guangdong Academy of Agricultural Sciences, Guangzhou 510640, China; sszxq@126.com (X.Z.); fwang1631@163.com (F.W.)

3 Innovative Center of Molecular Genetics and Evolution, School of Life Sciences, Guangzhou University, Guangzhou 510000, China; xn2112wjh@163.com

4 Key Laboratory of South China Agricultural Plant Molecular Analysis and Genetic Improvement, Guangdong Provincial Key Laboratory of Applied Botany, South China Botanical Garden, Chinese Academy of Sciences, Guangzhou 510650, China; yingchaoxu2021@163.com (Y.X.); illvm@163.com (Y.H.)

5 Institute of Plant Biology, National Taiwan University, Taipei 106, Taiwan; wayneyu2@yahoo.com.tw

6 Guangdong Key Laboratory for New Technology Research of Vegetables, Vegetable Research Institute, Guangdong Academy of Agricultural Sciences, Guangzhou 510640, China

* Correspondence: kewu@ntu.edu.tw (K.W.); yangsongguang@scbg.ac.cn (S.Y.)

+ These authors contributed equally to this work.

check for updates

Citation: Gao, S.; Zeng, X.; Wang, J.; Xu, Y.; Yu, C.; Huang, Y.; Wang, F.; Wu, K.; Yang, S. Arabidopsis SUMO E3 Ligase SIZ1 Interacts with HDA6 and Negatively Regulates HDA6 Function during Flowering. Cells 2021, 10, 3001 https://doi.org/10.3390/cells10113001

Academic Editor: Jianxin Shi

Received: 26 July 2021

Accepted: 31 October 2021

Published: 3 November 2021

Publisher's Note: MDPI stays neutral with regard to jurisdictional claims in published maps and institutional affiliations.

Copyright: (c) 2021 by the authors. Licensee MDPI, Basel, Switzerland. This article is an open access article distributed under the terms and conditions of the Creative Commons Attribution (CC BY) license (https:// creativecommons.org/licenses/by/ $4.0 /)$.
Abstract: The changes in histone acetylation mediated by histone deacetylases (HDAC) play a crucial role in plant development and response to environmental changes. Mammalian HDACs are regulated by post-translational modifications (PTM), such as phosphorylation, acetylation, ubiquitination and small ubiquitin-like modifier (SUMO) modification (SUMOylation), which affect enzymatic activity and transcriptional repression. Whether PTMs of plant HDACs alter their functions are largely unknown. In this study, we demonstrated that the Arabidopsis SUMO E3 ligase SAP AND MIZ1 DOMAIN-CONTAINING LIGASE1 (SIZ1) interacts with HISTONE DEACETYLASE 6 (HDA6) both in vitro and in vivo. Biochemical analyses indicated that HDA6 is not modified by SUMO1. Overexpression of HDA6 in siz1-3 background results in a decreased level of histone $\mathrm{H} 3$ acetylation, indicating that the activity of HDA6 is increased in siz1-3 plants. Chromatin immunoprecipitation (ChIP) assays showed that SIZ1 represses HDA6 binding to its target genes FLOWERING LOCUS $C$ (FLC) and MADS AFFECTING FLOWERING 4 (MAF4), resulting in the upregulation of FLC and $M A F 4$ by increasing the level of histone $\mathrm{H} 3$ acetylation. Together, these findings indicate that the Arabidopsis SUMO E3 ligase SIZ1 interacts with HDA6 and negatively regulates HDA6 function.

Keywords: HDA 6; SUMO E3 ligase SIZ1; flowering; Arabidopsis

\section{Introduction}

In eukaryotes, each nucleosome consists of $147 \mathrm{bp}$ of DNA wrapped twice around a cylindrical protein core containing two copies of each histone: H2A, H2B, H3, and H4 [1,2]. Histone proteins have a structured globular domain and an unstructured amino-terminal tail that protrudes from the core nucleosome. These histone tails can be altered through a variety of post-translational modifications (PTM) including acetylation, phosphorylation, methylation, ubiquitination, and ADP-ribosylation [3]. All these PTMs are reversible, and their dynamics are controlled by two classes of histone-modifying enzymes with opposing effects of addition and removal. Histone PTMs often play an important role in the regulation of various biological processes including transcription, DNA replication and repair, and chromatin dynamics $[4,5]$. 
The acetylation state of four core histones is reversible and highly dynamic, with the acetyl group transferred from acetyl-CoA to the $\mathrm{N}$ - $\varepsilon$-amino group of lysine residues by histone acetyltransferases (HAT) and removed by histone deacetylases (HDAC) [6]. In general, HATs act as transcriptional activators, since the acetylation of lysine residues in the histone tails can neutralize the positive charge of the nucleosome, thereby disrupting electrostatic interactions between histones and the phosphate groups of DNA, leading to a looser configuration [7,8]. In contrast, HDACs function as transcriptional repressors. Based on the sequence homology and substrate specificity, HDACs are grouped into three major classes in plants: REDUCED POTASSIUM DEPENDENCE 3/HISTONE DEACETYLASE 1 (RPD3/HDA1), SILENT INFORMATION REGULATOR 2 (SIR2) and HISTONE DEACETYLASE 2 (HD2)-related protein families [9]. A large number of studies support the idea that HDACs always associate with other nuclear factors including transcription factors to regulate gene expression [10-12]. For instance, HDA6, a member of the RPD3/HDA1 family, is recruited by the transcription factor ARABIDOPSIS PHANTASTICA-LIKE 1 (AS1) to regulate KNOTTED-LIKE HOMOBOX (KNOX) genes involved in leaf development [13]. HDA6 also associates with FLOWERING LOCUS D (FLD), a lysine-specific demethylase 1 (LSD1)-type histone demethylase, to regulate the expression of FLC, MAF4, and MAF5 in flowering control [14]. HDA6 and LSD1-LIKE 1/2 (LDL1/2) form a repressive complex by interacting with CIRCADIAN CLOCK ASSOCIATED 1 (CCA1)/LATE ELONGATED HYPOCOTYL (LHY) and TIMING OF CAB EXPRESSION 1 (TOC1) to repress TOC1 and CCA1/LHY expression, respectively $[15,16]$. HDA6 also maintains transposable element silencing through directly interacting with DNA METHYLTRANSFERASE 1 (MET1) and the H3K9 methyltransferases SU (VAR) 3-9 HOMOLOG 4/5/6 (SUVH4/5/6) [17,18]. Furthermore, phosphorylation of two serine residues-S427 and S429-of HDA6 results in increased enzymatic activity, whereas a mutation of S427 to alanine in HDA6 abolishes its interaction with SUVH5 and SUVH6, suggesting that the phosphorylation of HDA6 is important for its activity and function [18].

Many studies have demonstrated that the activity of HDACs is regulated by PTMs in mammalian cells [19]. For instance, cigarette smoke extracts (CSE) can induce the SUMOylation of K462 and K51 in HDAC2, and SUMOylated K51 decreases its activity [20]. Indeed, the conjugation of SUMO isoforms (e.g., SUMO1, SUMO2, SUMO3, and SUMO5 in Arabidopsis thaliana) to substrates is driven by an E1-E2-E3 enzymatic cascade [21,22]. The SUMO proteins are first acetylated and then bound via a high energy thioester linkage to the heterodimeric SUMO-activating enzyme (E1) [21]. The activated SUMO proteins were then transferred to the SUMO CONJUGATION ENZYME 1 (SCE1) (E2) via transesterification, and were finally donated to substrate proteins by a SUMO-protein ligase (E3). To date, only four Arabidopsis SUMO ligases (E3) have been described: SAP AND MIZ1 DOMAINCONTAINING LIGASE1 (SIZ1) [23,24], METHYL METHANESULFONATE-SENSITIVE21 (MMS21 or HIGHPLOIDY2) [25,26], PROTEIN INHIBITORS OF ACTIVATED STATs-LIKE1 (PIAL1), and PROTEIN INHIBITORS OF ACTIVATED STATs-LIKE2 (PIAL2) [27]. Previous studies demonstrated that SUMOylation mediated by SIZ1 has various roles in plant growth [28], secondary cell wall formation [29], flowering [30,31], light response [32,33], immunity [34,35], and metabolism of nutrient elements such as phosphate [23] and nitrogen [36]. Moreover, SIZ1 is implicated in glucose-controlled developmental traits including post-germination growth and root development [37]. Additionally, recent data indicated that SUMOylation mediated by SIZ1 is involved in plant responses to various stresses such as cold [38], heat [39] and drought [40], and is involved in hormone signaling processes such as abscisic acid [41,42], auxin [43], gibberellin [44], and brassinosteroid signaling pathways [45].

In Arabidopsis, proteomic data identified a large number of conjugates for SUMO1/ SUMO2 mediated by SIZ1 [39,46,47]. Among these, a number of the targets are known to associate with multi-subunit protein complexes including the TOPLESS (TPL) complex, the SWI/SNF chromatin remodeling complex [39], and histone deacetylation-related complexes $[39,46]$. However, the functions of the proteins SUMOylated by SIZ1 are largely 
unknown. In the present study, we show that SIZ1 interacts with HDA6 and modulates its function. Overexpression of HDA6 in the siz1-3 mutant results in a decreased level of H3 acetylation of the HDA6 target genes FLC and MAF4 compared to the wild-type (WT). Together, these findings indicate that the Arabidopsis SUMO E3 ligase SIZ1 interacts with HDA6 and negatively regulates HDA6 function.

\section{Materials and Methods}

\subsection{Plant Materials and Growth Conditions}

All Arabidopsis seeds used in this study are in the Columbia background (Col-0). The hda6 mutant line axe1-5 [14] and siz1 mutant siz1-3 [30] were obtained from the Arabidopsis Information Resource Center (http:/ / www.arabidopsis.org/; accessed on 7 July 2014). proHDA6:HDA6-GFP transgenic plants were described previously [18]. The full-length cDNA of HDA6 and SIZ1 were PCR-amplified and cloned into the pCAMBIA1302 and pHB binary vector, respectively. The pro35S:HDA6-GFP (HDA6-OE) and pro35S:SIZ1FLAG transgenic plants were generated using the floral dip method [48]. Double mutants were generated by genetic crossing, and the axe1-5 siz1-3 double mutant was generated according to Barth's method [49]. Briefly, crossing homozygous axe1-5 and siz1-3 mutants with one another resulted in $\mathrm{F}_{1}$ progeny that contained both mutations in the repulsion phase. The outcross progeny, which were generated by crossing the $F_{1}$ plants from the first cross to the male-sterile ap3-6 mutant [50], were screened by flowering phenotype. The delayed flowering but smaller plants were potentially heterozygous for both mutations. Progeny from these lines were analyzed by PCR for homozygosity of both axe1-5 and siz1-3. $\mathrm{F}_{2}$ progeny that were homozygous axe1-5 siz1-3 and AP3/AP3 were selected for further analysis. All plants were germinated and grown under normal growth light $(150-200 \mu \mathrm{mol}$ photons $\left.\mathrm{m}^{-2} \mathrm{~s}^{-1}\right)$ at $22{ }^{\circ} \mathrm{C}$ under LD (16/8 h light/dark cycle) conditions. A Murashige and Skoog basal salt mixture (MS) with 1.5\% sucrose was used as a nutrient source for sample collection.

\subsection{Gene Expression Analysis}

Total RNA was extracted with Trizol reagent (Invitrogen, Carlsbad, CA, USA) according to the manufacturer's protocol. The first-strand cDNA was synthesized using reverse transcriptase (Takara, Dalian, China). Quantitative PCR (qPCR) analysis was performed using the SYBR Green PCR Supermix (Bio-Rad Laboratories, Hercules, CA, USA) on an ABI7500 Real-Time PCR System (Applied Biosystems, Foster, CA, USA). Each sample was quantified at least in triplicate and normalized using UBQ10 or ACTIN2 as an internal control. The gene specific primer pairs for qPCR are listed in Supplementary Table S1. Three biological replicates were performed for qPCR analysis and representative results from one biological replicate are shown.

\subsection{Protein-Protein Interaction Assay}

Yeast two-hybrid assays were performed according to the Matchmaker GAL4-based two-hybrid system 3 protocol (Clontech, San Francisco, CA, USA). The full-length of HDA6 and SIZ1 coding sequences (CDS) were subcloned into pGADT7-AD and pGBKT7-BD vectors, respectively. The primers used for the constructs are listed in Supplementary Table S1. The paired AD and BD constructs were co-transformed into yeast strain AH109 using the lithium acetate method [51] and plated on DDO medium (minimal media double dropouts, SD medium lacking tryptophan and leucine) for 3 days at $30{ }^{\circ} \mathrm{C}$. Transformed colonies were plated onto TDO medium (minimal media triple dropouts, SD medium lacking tryptophan, leucine and histidine) containing $40 \mu \mathrm{g} \mathrm{mL}{ }^{-1}$ of 5-bromo-4-chloro-3indoyl- $\alpha$-D-galactosidase $(\mathrm{TDO} / \mathrm{X})$ to test for possible interactions between HDA6 and SIZ1 under the same conditions.

For BiFC assays, the full-length of both HDA6 and SIZ1 CDS was subcloned into the pCR8/GW/TOPO vectors and recombined into YN (pEarleyGate201-YN) and YC (pEarleyGate202-YC) vectors [52], respectively. The YN and YC constructs were used for 
transient assays by polyethylene glycol (PEG) transfection of Arabidopsis protoplasts [53]. Transfected cells were imaged using the TCS SP5 Confocal Spectral Microscope Imaging System (Leica).

Co-immunoprecipitation assay (Co-IP) assays were performed as described previously [54]. A. tumefaciens harboring $p E A Q-G F P, p E A Q-H D A 6-G F P, p E A Q-G F P-H D A 6$, and $p H B-S I Z 1-F L A G$ was infiltrated into at least six leaves of tobacco. After $36 \mathrm{~h}$ infiltration, tobacco leaves were harvested and ground to a fine powder in liquid nitrogen. Proteins were extracted in an extraction buffer $(50 \mathrm{mM}$ Tris- $\mathrm{HCl}, \mathrm{pH} 7.4,150 \mathrm{mM} \mathrm{NaCl}, 2 \mathrm{mM}$ $\mathrm{MgCl}_{2}, 1 \mathrm{mM}$ DTT, 20\% glycerol, and 1\% NP-40) containing protease inhibitor cocktail (Roche, Basel, Switzerland). Cell debris was pelleted by centrifugation at $14,000 \times g$ for 20 min. The supernatant was incubated with $30 \mu \mathrm{L}$ of GFP-Trap ${ }^{\circledR}$-A beads (Chromo Tek, Planegg-Martinsried, Germany) at $4{ }^{\circ} \mathrm{C}$ for $4 \mathrm{~h}$. Then, the beads were centrifuged and washed six times with a washing buffer $(50 \mathrm{mM}$ Tris- $\mathrm{HCl}, \mathrm{pH} 7.4,150 \mathrm{mM} \mathrm{NaCl}, 2 \mathrm{mM}$ $\mathrm{MgCl}_{2}, 1 \mathrm{mM}$ DTT, $10 \%$ glycerol, and 1\% NP-40). Proteins were eluted with $30 \mu \mathrm{L}$ of $2 \times$ loading buffer and analyzed by Western blotting using anti-GFP (TransGen, HT801-01, Beijing, China) and anti-FLAG antibodies (TransGen, HT201-01, Beijing, China).

\subsection{Histone Preparations}

Histones were isolated from 15-day-old seedlings using sulfuric acid extraction of nuclei followed by acetone precipitation [55]. About $2 \mathrm{~g}$ of fresh seedlings were ground in liquid nitrogen, and then $10 \mathrm{~mL}$ of NIB buffer $(15 \mathrm{mM} \mathrm{NaCl}, 1 \mathrm{mM} \mathrm{CaCl} 2,60 \mathrm{mM}$ $\mathrm{KCl}, 5 \mathrm{mM} \mathrm{MgCl}, 0.7 \mu \mathrm{g} / \mathrm{mL}$ pepstatin, $1 \mathrm{mM}$ phenylmethylsulfonyl fluoride (PMSF), complete mini-Table protease inhibitors (Roche, Basel, Switzerland), $0.8 \%$ Triton X-100, and $15 \mathrm{mM}$ PIPES pH 6.8, $0.25 \mathrm{M}$ sucrose) were added. The mixture was filtered through Micra cloth and then centrifuged at $10,000 \times g$ for $25 \mathrm{~min}$ at $4{ }^{\circ} \mathrm{C}$. The nuclei were then extracted twice with $0.4 \mathrm{M} \mathrm{H}_{2} \mathrm{SO}_{4}$ and precipitated with 12 volumes of acetone. The precipitate was collected by centrifugation at $12,000 \times \mathrm{g}$ for $25 \mathrm{~min}$ at $4{ }^{\circ} \mathrm{C}$. The pellet was dissolved in $200 \mu \mathrm{L}$ of $4 \mathrm{M}$ urea.

\subsection{ChIP Assays}

ChIP assays were performed as previously described [56,57]. Chromatin was extracted from 15-day-old seedlings (about $0.3 \mathrm{~g}$ ) after fixation with formaldehyde, and the chromatin was extracted and then sheared to an average length of $500 \mathrm{bp}$ by sonication. The chromatin was immunoprecipitated with specific antibodies including anti-H3ac (Millipore, 06-599), anti-H3K9ac (Millipore, 07-352, Burlington, MA, USA), and anti-GFP (Abcam, ab290, Cambridge, UK)). An equal amount of the sonicated chromatin solution was set aside as the input sample. After cross-linking was reversed, the amount of precipitated DNA fragments and input DNA was detected by qPCR using specific primers listed in Supplementary Table S1. The relative enrichment of various regions of FLC and MAF4 in mutants over Col-0 was calculated after normalization to ACTIN2. The percentage input was calculated by determining $2^{-\Delta \mathrm{Ct}}=2^{-[\mathrm{Ct}}{ }_{(\mathrm{ChIP})}{ }^{-\mathrm{Ct}}{ }_{\text {(Input) }}{ }^{]}$. The exon region of retrotransposon TA3 [58] was used as a negative control.

\subsection{SUMOylation Assay}

A SUMOylation assay in Escherichia coli was performed as previously described [59,60]. The full-length CDS of HDA6 was cloned into pET28 (a), generating a FLAG C-terminal tag and expressed in the bacteria carrying $p C D F D u e t-1-A t S A E 1 a-A t S A E 2$ (E1) with $p A C Y C D u e t-$ 1-AtSCE1-AtSUMO1GG or PACYCDuet-1-AtSCE1 (C94S)-SUMO1GG (E2 and SUMO1) [61]. The transformed cells were cultured in $\mathrm{LB}$ medium to an $\mathrm{OD}_{600}$ of 0.5 and induced by $0.5 \mathrm{mM}$ isopropylthio- $\beta$-galactoside. After incubation for $12 \mathrm{~h}$ at $25^{\circ} \mathrm{C}$, cells were harvested and used for immunoblotting by anti-FLAG antibody (Sigma, Burlington, MA, USA). MYB30 and HDA19 were used as positive control [46,59]. 


\subsection{Statistical Analysis}

Data represent the means \pm standard error (SE). Differences among treatments were compared by one-way ANOVA followed by a post hoc test with statistical significance set at the level of $p<0.05$. Statistical analysis was performed using SPSS v16.0 (SPSS Inc., Chicago, IL, USA).

\section{Results}

\subsection{SUMO E3 Ligase SIZ1 Interacts with HDA6 In Vitro and In Vivo}

Previous proteomic data demonstrated that HDA19 conjugates with SUMO1/SUMO2 mediated by SIZ1 [46,47]. Since HDA6 is a close homolog of HDA19, we hypothesized that HDA6 may also be a target of SIZ1. Thus, yeast two-hybrid assays were used to detect the interaction between HDA6 and SIZ1. Yeast cells co-transformed with SIZ1-AD (full-length CDS of SIZ1 fused to pGAKT7) and HDA6-BD (full-length CDS of HDA6 fused to pGBKT7) were able to grow on the selective medium TDO (minimal media triple dropouts, SD medium lacking tryptophan, leucine and histidine), indicating that SIZ1 could interact with HDA6 in yeast cells (Figure 1A). Similar results were observed when SIZ1 and HDA6 were fused to pGBKT7 and pGAKT7, respectively (Figure 1A).

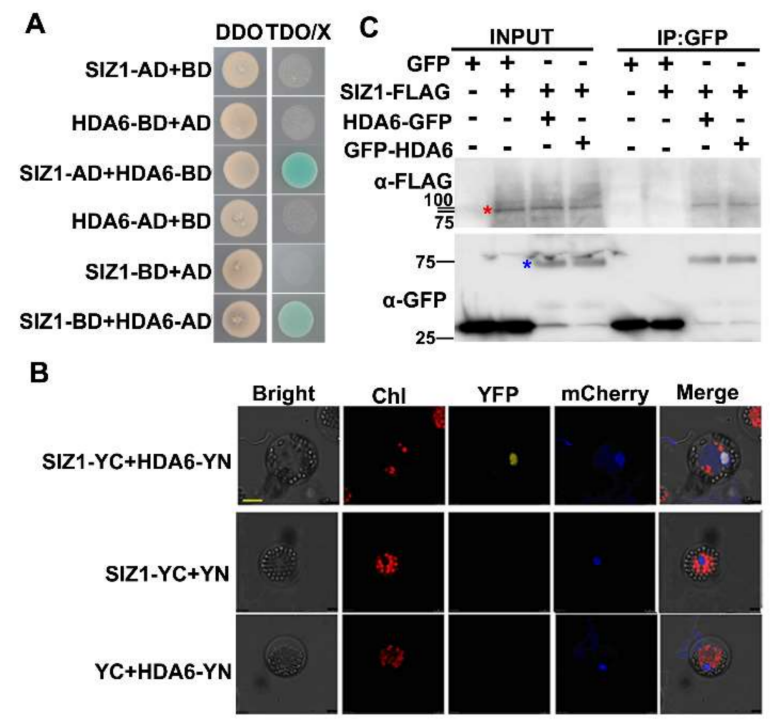

Figure 1. HDA6 interacts with SIZ1 both in vitro and in vivo. (A) Yeast two-hybrid analysis of HDA6SIZ1 interaction. The full-length CDS of HDA6 and SIZ1 fused with both the GAL4 activation domain (AD) and GAL4 DNA binding domain (BD) vectors, respectively, and were co-transformed into yeast cells and plated on a DDO medium. The transformants were then plated on TDO $/ \mathrm{X}$ medium at $30^{\circ} \mathrm{C}$ to test for a possible interaction. DDO-minimal media double dropouts and the SD medium lacking tryptophan and leucine; TDO-minimal media triple dropouts and SD medium lacking tryptophan, leucine and histidine; TDO/X-TDO medium containing $40 \mu \mathrm{g} \mathrm{mL}^{-1}$ 5-bromo-4-chloro-3-indoyl$\alpha$-D-galactosidase. (B) BiFC analysis of the interaction between HDA6 and SIZ1 in Arabidopsis protoplasts. SIZ1 and HDA6 were fused with the C-terminus (YC) or the N-terminus (YN) of YFP and co-transformed into Arabidopsis protoplasts by PEG-mediated transformation. Empty vectors were used as negative controls. The mCherry was used as a nuclear marker. Chl-auto-fluorescence of chlorophyll. Bars $=25 \mu \mathrm{m}$. (C) Co-IP analysis of the interaction between HDA6 and SIZ1. The GFP, HDA6-GFP, GFP-HDA6, and SIZ1-FLAG co-expressed in tobacco leaves by Agrobacterium injection. Total protein extracts were immunoprecipitated with GFP-Trap-A beads and the immunoprecipitated protein was then detected by Western blotting assays using an anti-FLAG antibody. Input HDA6-GFP and SIZ1-FLAG proteins were detected with anti-GFP and anti-FLAG antibodies, respectively. The molecular weight $(\mathrm{kDa})$ is indicated in the right panel. IP-immunoprecipitation. Red and blue asterisks indicate SIZ1-FLAG and HDA6-GFP (or GFP-HDA6), respectively. 
Next, the interaction between SIZ1 and HDA6 was examined in vivo by bimolecular fluorescence complementation (BiFC) and co-immunoprecipitation (Co-IP) assays. SIZ1 and HDA6 were cloned in the YC (pEarleygate-YC) and YN (pEarley gate-YN) vectors, respectively. The YN and YC constructs were then co-delivered into Arabidopsis protoplasts. The mCherry carrying a nuclear localization signal was used as a nuclear marker. As shown in Figure 1B, strong YFP signals were observed in the nucleus of Arabidopsis protoplasts, suggesting that SIZ1 and HDA6 interact in plant cells. For the Co-IP assays, HDA6-GFP or GFP-HDA6 and SIZ1-FLAG constructs were co-expressed into tobacco leaves for analysis. An anti-GFP antibody was used for immunoprecipitation, and the immunoprecipitated proteins were then analyzed by Western blotting assays using an anti-FLAG antibody. Consistent with our previous IP mass data using proHDA6:HDA6-GFP transgenic plants [18], the SIZ1-FLAG was co-immunoprecipitated by both HDA6-GFP and GFPHDA6 (Figure 1C). Similar results were also observed using transgenic plants coexpressing 35S:HDA6-GFP and 35S:SIZ1-FLAG (Supplemental Figure S1). These results indicate that SIZ1 interacts with HDA6 both in vitro and in vivo. Notably, two clear bands were detected in the input panel of transgenic plants indicating that SIZ1 may be altered by PTMs in Arabidopsis. Indeed, previous proteomic data also demonstrated that SIZ1 can be altered by phosphorylation [62] and SUMOylation [46]. Although the high-molecular-weight form of SIZ1-FLAG was immunoprecipitated by HDA6-GFP, it remains to be determined which PTMs it contains.

Since SIZ1 is a SUMO E3 ligase, we further investigated whether HDA6 can be SUMOylated. First, a rapid method to check the SUMOylation of HDA6 using a reconstituted SUMOylation system with Arabidopsis SUMO machinery proteins in Escherichia coli was used [59]. Along with a SUMO1 isoform, two types of plasmids were constructed: pACYCDuet, which carried the two protein subunits of the E1 heterodimer, SAE1b and SAE2; and pCDFDuet-1, which carried E2 (SCE1a or an inactive SCE1a-Cys-94-to-Ser (C94S) version of E2 [61]). HDA6 was cloned into the pET28(a) vector to fuse a FLAG-tag at its Cterminus by PCR. The transcription factors MYB30 and HDA19, two known SUMO target proteins, were used as positive controls [46,59]. The constructed plasmids $p A C Y C D$ uetSAE1b-SAE2, pCDFDuet-SUMO1-SCE1a (or SCE1a (C94S)) and pET28(a)-HDA6-FLAG were co-transformed into Escherichia coli BL21 (DE3) cells. An anti-FLAG antibody was used to detect the SUMOylation of HDA6. Consistent with previous proteomic data, in vitro SUMOylation reactions resulted in an identical pattern of conjugate bands for HDA19 and MYB30 but not HDA6 (Supplemental Figure S2A). These results indicated that HDA6 may not be a SUMOylation target protein, which is consistent with the predicted results using GPS-SUMO software (http://sumosp.biocuckoo.org/index.php, accessed on 28 October 2021) [63]. Although proteomic data demonstrated that the HDA6 homolog HDA19 is conjugated with SUMO1/SUMO2, the SUMOylation sites of HDA19 were not mapped [46,47]. Nevertheless, it was predicted that the SUMOylation site of HDA19 is located at the C-termini, as HDA6 lacks this motif (Supplemental Figure S2B). Next, proHDA6:HDA6-GFP [18] was introduced to siz1-3 plants by crossing. No difference was found in the level of HDA6-GFP between WT (Col-0) and siz1-3 (Supplemental Figure S2C), indicating that the expression or stability of HDA6 is not affected by SIZ1.

\subsection{HDA6 Acts Downstream of SIZ1 to Repress FLC}

To explore the function of the interaction between HDA6 and SIZ1, an axe1-5 siz1-3 double mutant was generated. Since HDA6 (AT5G63110) and SIZ1 (AT5G60410) were located in the same chromosome, we used a crossing scheme to select double mutants, which was used previously to find meiotic recombination between tandemly-duplicated genes TGG1 and TGG2 in genus Arabidopsis [49]. Briefly, the $\mathrm{F}_{1}$ progenies resulting from crossing HDA6 mutant axe1-5 [14] and siz1-3 [30] were chosen as the pollen donors for the second cross to the male-sterile ap3-6 mutant [50]. $\mathrm{F}_{2}$ progenies that were homozygous axe1-5 siz1-3 were identified by PCR and phenotyping. 
Consistent with previous studies, axe1-5 mutant plants exhibited delayed-flowering phenotypes [14], while siz1-3 showed an earlier-flowering phenotype [30]. The axe1-5 siz1-3 double mutant plants displayed a late flowering phenotype similar to axe1-5 under long-day conditions (LD, 16/8 h light/dark) (Figure 2A). Similar results were observed when axe1-5 siz1-3 plants were grown under short-day conditions (SD, 8/16 light/dark) (Supplemental Figure S3). Next, we also compared the rosette leaf numbers of axe1-5, siz1-3 and the double mutant axe1-5 siz1-3. The flowering time of axe1-5 siz1-3 and axe1-5 plants was delayed under LD in terms of the number of rosette leaves at bolting (Figure 2B). In addition, the expression of $F L C$ and its clade member MAF4, two target genes regulated by HDA6, was significantly upregulated in axe1-5 siz1-3 and axe1-5 plants. Meanwhile, the mRNA levels of MAF1 and MAF5 were also significantly increased in the axe1-5 siz1-3 mutant compared to WT and siz1-3 plants (Figure 2C). Consistent with previous findings [30], the expression of FLC and MAF4 decreased in siz1-3 plants, which may account for the early flowering phenotype of siz1-3 plants. Collectively, these results indicate that HDA6 acts downstream of SIZ1 in flowering. Previously, we reported that axe1-5 displayed serrated and twisted leaves under LD conditions [13]. Similar curling and serrated leaves were found in siz1-3 plants (Supplemental Figure S4). Furthermore, axe1-5 siz1-3 plants showed more severe curling and serrated leaves compared to the single mutants (Figure 2A, Supplemental Figure S4), suggesting that HDA6 and SIZ1 act additively to regulate leaf development.

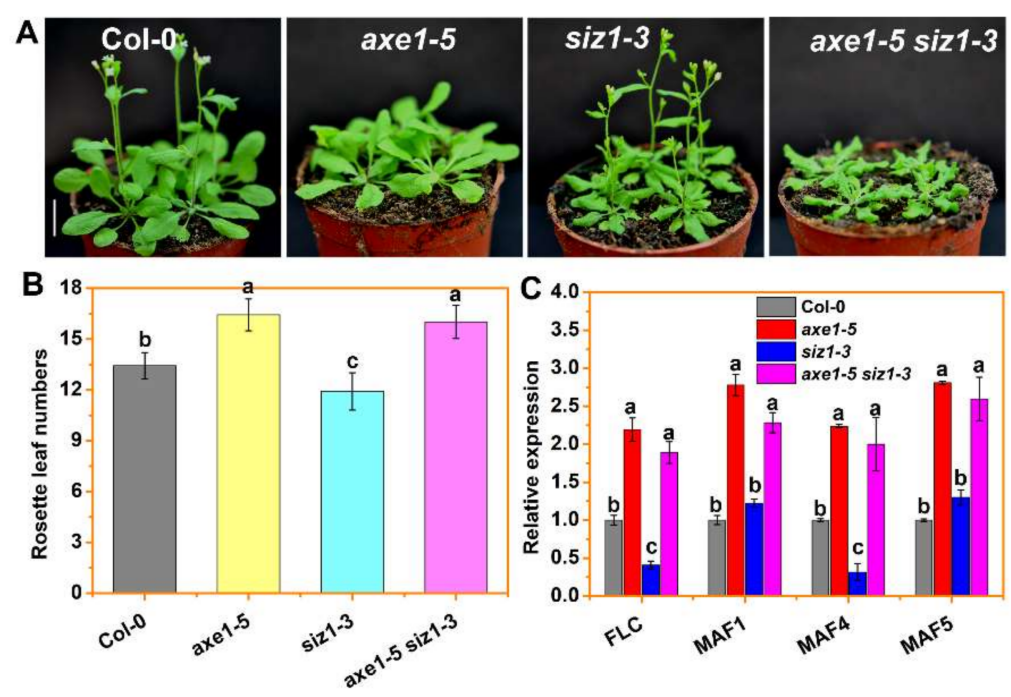

Figure 2. HDA6 acts downstream of SIZ1 to repress FLC and MAF4. (A) Flowering phenotypes of 21-day-old WT(Col-0), axe1-5, siz1-3, and axe1-5 siz1-3 plants under LD. Bars = $1 \mathrm{~cm}$. (B) Rosette leaf numbers at flowering for WT, axe1-5, siz1-3, and axe1-5 siz1-3 plants under LD. Data are the averages \pm SE of three independent replicates and at least 20 plants were scored for each line. Different letters are used to indicate means that are significantly different $(p<0.05$, post hoc test). (C) qRT-PCR analysis of the expression levels of FLC and MAFs in 15-day-old WT, axe1-5, siz1-3, and axe1-5 siz1-3 plants under LD conditions. ACTIN2 was used as an internal control. Values are shown as means \pm SE. Different letters are used to indicate means that are significantly different $(p<0.05$, post hoc test). Three independent biological replicates were performed, with similar results obtained.

\subsection{The H3ac and H3K9ac Levels of MAF4 and FLC Are Decreased in siz1-3 Plants}

HDA6 is a member of the RPD3/HDA1 group histone deacetylases, which target H3ac and H3K9ac for deacetylation in plants $[14,18,64]$. Since the SUMO E3 ligase SIZ1 interacts with HDA6 but does not SUMOylate HDA6, we determined whether the deacetylase activity of HDA6 could be inhibited by SIZ1. The deacetylase activity of HDA6 was determined by Western blot (WB) analysis using proHDA6:HDA6-GFP transgenic plants, in which HDA6 was overexpressed (Supplemental Figure S5). The immunoblot analysis indicated that $\mathrm{H} 3 \mathrm{ac}$ and $\mathrm{H} 3 \mathrm{~K} 9 \mathrm{ac}$ levels of axe1-5 were increased compared to WT 
(Figure 3A), which is consistent with findings in previous study [14,18,64]. However, the H3ac and H3K9ac levels of proHDA6:HDA6-GFP siz1-3 plants were decreased compared to WT and proHDA6:HDA6-GFP plants (Figure 3A), indicating that the activity of HDA6 was increased with a siz1-3 background. Moreover, the H3ac levels were decreased in siz1-3 but increased in axe1-5 siz1-3 compared to WT (Supplemental Figure S6A). Notably, genome-wide reductions in $\mathrm{H} 3 \mathrm{ac}$ and $\mathrm{H} 3 \mathrm{~K} 9 \mathrm{ac}$ levels did not cause any visible phenotype changes in proHDA6:HDA6-GFP compared to WT (Supplemental Figure S7).

A

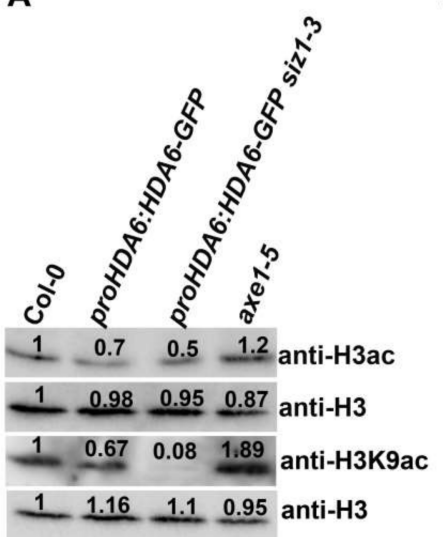

B

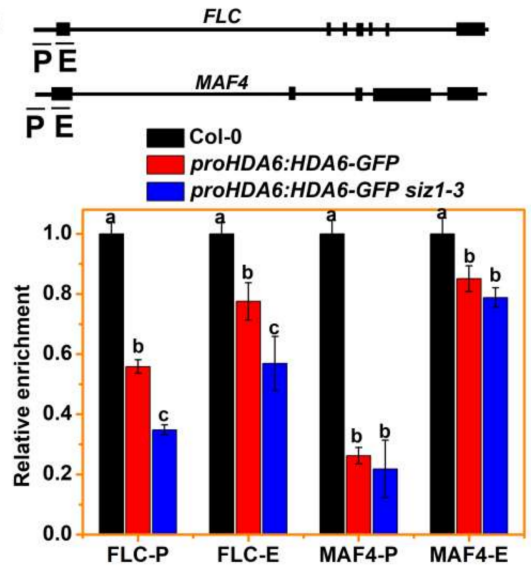

Figure 3. SIZ1 inhibits the activity of HDA6 during flowering. (A) Immunoblot analyses of total histone extracted from 15-day-old plants of WT, proHDA6:HDA6-GFP , proHDA6:HDA6-GFP siz1-3, and axe1-5 with indicated antibodies. Histone $\mathrm{H} 3$ antibody is shown as a loading control. The numbers shown on the gels represent the quantitative results (in arbitrary units). (B) Overexpression of HDA6 decreased the H3ac level on FLC and MAF4 loci. Upper panel: Schematic diagram of FLC and MAF4 loci. $\mathrm{P}$ and $\mathrm{E}$ represent the promoter and first exon region, respectively. Lower panel: ChIP analysis of H3ac levels on the FLC and MAF4 loci. Fifteen-day-old plant samples were collected for further analysis. The amounts of DNA after ChIP were quantified by qPCR and normalized to ACTIN2. Error bars correspond to standard deviations from three biological replicates. Different letters above bars indicate a significant difference between the mutant and WT $(p<0.05$, post hoc test).

Next, we investigated whether overexpressing HDA6 affects the level of H3ac on its target loci such as FLC and MAF4 [14], by chromatin immunoprecipitation followed by quantitative PCR (ChIP-qPCR). Several HDA6 binding regions of FLC and MAF4, including their promoters and first exons, were selected for ChIP-qPCR analysis (Figure 3B). We found that the H3ac level of FLC and MAF4 was decreased in proHDA6:HDA6-GFP plants in the proximal promoter and first exon regions (Figure 3B), especially in proHDA6:HDA6GFP siz1-3 plants compared to WT (Figure 3B). In contrast, the H3ac levels of FLC and $M A F 4$ were increased in axe1-5 plants in these genomic regions (Supplemental Figure $\mathrm{S6B})$, which is consistent with the increased expression of FLC and MAF4 in axe1-5 plants. However, the H3ac level of FLC and MAF4 in axe1-5 siz1-3 was lower than that of axe1-5, suggesting that in addition to HDA6, SIZ1 may also regulate the activity of some other histone acetylation enzymes.

\subsection{SIZ1 Represses HDA6 Binding to Its Target during Flowering}

We performed ChIP-qPCR assays using proHDA6:HDA6-GFP plants to investigate whether SIZ1 affects the binding profile of HDA6. ChIP-qPCR assays were performed with the anti-GFP antibody and the binding of HDA6 to its target loci, FLC and MAF4, was analyzed by qPCR. Consistent with previous findings [14], HDA6-GFP was significantly enhanced in the first exon and promoter regions of FLC and MAF4 (Figures 3B and 4A). In addition, the binding of HDA6 was analyzed in proHDA6:HDA6-GFP siz1-3 plants. The binding of HDA6 to the FLC and MAF4 loci was significantly increased in proHDA6:HDA6GFP siz1-3 compared to proHDA6:HDA6-GFP plants (Figure 4A), suggesting that binding of 
HDA6 to the FLC and MAF4 loci is repressed by SIZ1. Furthermore, the expression of FLC and MAF4 in both proHDA6:HDA6-GFP and proHDA6:HDA6-GFP siz1-3 plants were significantly reduced compared with WT (Figure 4B). In addition, the expression of FLOWERING LOCUS T (FT) and SUPPRESSOR OF OVEREXPRESSION OF CO 1 (SOC1), two key genes at the convergence of flowering, was significantly increased in proHDA6:HDA6-GFP siz1-3 plants compared to WT, but not in proHDA6:HDA6-GFP plants (Figure 4B).
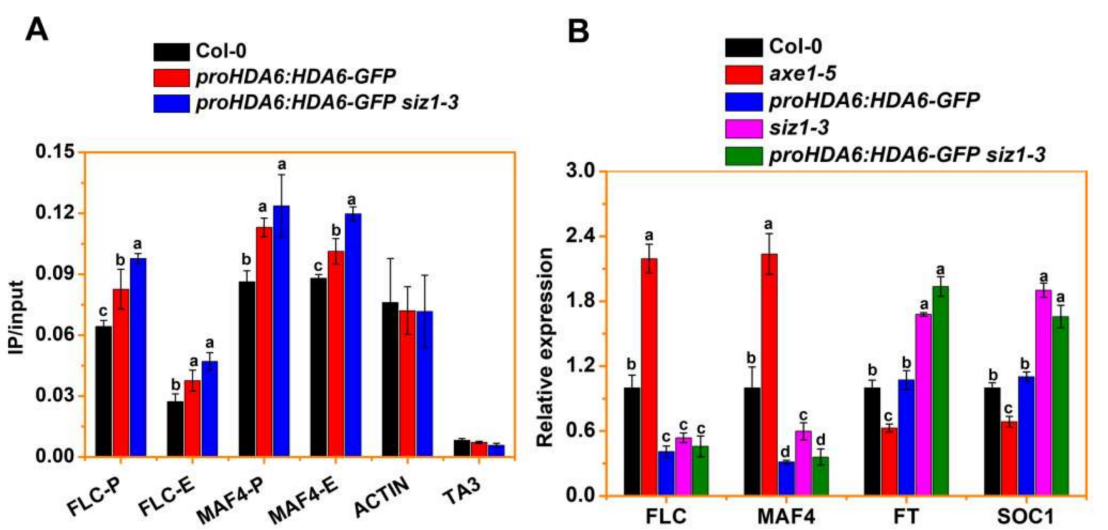

Figure 4. SIZ1 inhibits HDA6 binding to FLC and MAF4 loci. (A) ChIP-qPCR analysis of proHDA6:HDA6-GFP siz1-3 DNA fragments co-immunoprecipitated with the anti-GFP antibody in FLC and MAF4 chromatin. Relative enrichment was calculated based on IP/input for each sample. TA3 and ACTIN2 were used as the negative control. Values are shown as means \pm SE. Error bars correspond to standard deviations from three biological replicates. Different letters are used to indicate means that are significantly different between mutant and WT treatments $(p<0.05$, post hoc test). (B) qRT-PCR analysis of the expression levels of $F L C, M A F 4, F T$, and $S O C 1$ in 15-day-old WT, axe1-5, proHDA6:HDA6-GFP, siz1-3, and proHDA6:HDA6-GFP siz1-3 plants under LD conditions. $A C T I N 2$ was used as an internal control. Values are shown as means $\pm \mathrm{SE}$. Error bars correspond to standard deviations from three biological replicates. Different letters are used to indicate means that are significantly different between mutant and WT ( $p<0.05$, post hoc test).

\section{Discussion}

Histone deacetylation mediated by HDACs is generally associated with transcriptional repression and gene silencing [10,65-67]. By acting as global transcriptional regulators, HDACs always associate with other nuclear proteins (such as transcription factors or chromatin factors) to regulate the expression of genes in plant development and plant response to environmental changes $[11,13,14,18,65-67]$. Furthermore, activities and functions of HDACs are regulated by PTMs, for example, phosphorylation and SUMOylation in mammalian cells [19,68]. In plants, recent studies indicated that phosphorylation of HDA6 can increase its enzymatic activity [18]. Furthermore, proteomic analysis demonstrated that the HDA6 homolog HDA19 is conjugated with SUMO1/SUMO2 mediated by SIZ1 [46,47]. These results indicated that PTMs may also be essential to the functions of HDACs in plants. Our results showed that the SUMO E3 ligase SIZ1 can interact with HDA6 both in vitro and in vivo (Figure 1, Supplemental Figure S1). However, the SUMOylation assays showed that HDA6 is not modified by SUMO1 (Supplemental Figure S2A). SUMOylated proteins typically contain a SUMO modification consensus motif, $\varphi \mathrm{KxE}$, in which $\varphi$ is an aliphatic residue, preferably $\mathrm{L}, \mathrm{I}$ or $\mathrm{V} ; \mathrm{K}$ is lysine; $\mathrm{X}$ is any residue; and $\mathrm{E}$ is glutamate [19]. This motif is found within the C-termini of human HDAC1 and HDAC2 (two SUMOylated proteins) [19]. The SUMOylation sites of HDAC1 were mapped on lysine K444 (VK $\left.{ }^{444} \mathrm{TE}\right)$ and $\mathrm{K} 476\left(\mathrm{VK}^{476} \mathrm{EE}\right)$, and the enzymatic activity and transcriptional repression are affected in the double SUMOylation mutant K444R, K476R (2R) on HDAC1 [69]. HDAC2 has a typical $\varphi \mathrm{KxE}$ motif $\left(\mathrm{VK}^{462} \mathrm{EE}\right)$ in its unstructured C-terminal domain, which has been identified as a target site for SUMOylation by SUMO1 both in vitro and in vivo [70]. The SUMOylation of HDAC2 is required for NF- $\mathrm{KB}$-dependent gene expression in transformed and primary 
cells [71]. Notably, although proteomic data demonstrated that the HDA6 homolog HDA19 is conjugated with SUMO1/SUMO2, its SUMOylation sites were not detected [46,47]. Although a predictive consensus motif, $\mathrm{VK}^{482} \mathrm{ME}$, was found at the C-terminus of HDA19, Arabidopsis HDA6 lacks this motif (Supplemental Figure S2B). Furthermore, the expression or stability of HDA6 is not affected by SIZ1 (Supplemental Figure S2B).

In Arabidopsis, complex and intricate gene-regulatory networks of transcription regulators guide the flowering time and flower development by integrating both internal and external signals [72]. During flowering, FLC, FLC homologues (such as FLOWERING LOCUS M, MAF2 and MAF4), and the MADS box transcription factor SHORT VEGETATIVE PHASE (SVP), act as negative regulators of flowering time. Generally, high mRNA levels of $F L C$ (or MAFs) result in later flowering associating with low expression of $F T$ and SOC1. However, the paradoxical expression pattern of FLC (or MAF4) and FT / SOC1 was also observed in brahma mutants, in which the expression levels of FLC, FT and SOC1 were all significantly increased and this was associated with early flowering [73,74]. In accordance with these observations, our results showed that a lower level of $\mathrm{H} 3 \mathrm{ac}$ and $\mathrm{H} 3 \mathrm{~K} 9 \mathrm{ac}$ was associated with reduced expression of FLC and MAF4, but that this does not lead to earlier flowering in proHDA6:HDA6-GFP and proHDA6:HDA6-GFP siz1-3 plants (Figure 3, Supplemental Figure S7). Consistent with their early flowering phenotypes, the levels of $F T$ and SOC1 transcripts are increased in proHDA6:HDA6-GFP siz1-3 plants compared to siz1-3 plants, while the expression of $F T$ and $S O C 1$ is unchanged in proHDA6:HDA6-GFP plants compared to WT (Figure 4B). Indeed, FLC, SVP, and MAFs can form several tetrameric repressor complexes with different compositions, such as FLC-SVP-MAF3-MAF4 and SVP-FLM-MAF2-MAF4, to which directly repress the expression of FT and SOC1 [75-77]. Moreover, biochemical and genetic results demonstrated that SUMOylation of FLC has a critical role in the regulation of flowering time [31]. Collectively, these results indicate that the modulation of protein levels of SVP and/or FLC clade members that lead to a change in the abundance of a particular complex comprising FLC, MAFs, and/or SVP in response to environmental and endogenous cues, may play a key role in the regulation of flowering time. More experiments are required to explore the roles of HDA6-SIZ1 module in the regulation of FLC and MAFs in Arabidopsis.

Previous studies demonstrated that HDA6 interacts with the histone demethylase FLD and binds to the chromatin of FLC and MAF4 [14]. Meanwhile, SIZ1-mediated SUMO modification of FLD may repress $\mathrm{H} 4$ deacetylation of $F L C$ chromatin [30]. These findings suggest that HDA6 and FLD may function with SIZ1 to regulate histone deacetylation and demethylation during flowering. Furthermore, genetic analysis indicated that $H D A 6$ and FLD act downstream of SIZ1 during flowering (Figure 2) [30], suggesting that SIZ1 is required for the function of HDA6 and FLD. Indeed, overexpression of HDA6 in siz1-3 plants caused lower levels of H3ac and H3K9ac compared to WT (Supplemental Figure S5, Figure 3A), indicating that the activity of HDA6 was increased in siz1-3. ChIP-qPCR data demonstrated that the binding of HDA6 to the FLC and MAF4 loci was significantly increased in proHDA6:HDA6-GFP siz1-3 compared to proHDA6:HDA6-GFP plants (Figure 4A), suggesting that SIZ1 represses the binding of HDA6 to its target loci. Thus, the lower levels of H3ac and $\mathrm{H} 3 \mathrm{~K} 9 \mathrm{ac}$ in Col-0 background may be caused by increased binding of HDA6 to chromatin, which is repressed by the interaction with SIZ1. However, since SIZ1 also mediates SUMO modification of other histone acetylation modification enzymes, such as the histone acetyltransferases GCN5 and HAC1, and the histone deacetylase HDA19 [39,46,47], the changes in histone acetylation in siz1-3 may not be caused by HDA6 alone. Furthermore, a recent study indicated that the PHD finger of Arabidopsis SIZ1 recognizes the trimethylated histone H3K4, which mediates the SIZ1 function and abiotic stress response [78]. In human cells, recognition of H3K4me3 by the PHD domains of the ING (for inhibitor of growth) family of tumor suppressor proteins stabilizes the HDAC complex to repress active genes in response to DNA damage [79]. Further research is required to investigate how SIZ1 affects HDAC activity and binding to the target genes. 
Similar to axe1-5 plants, the axe1-5 siz1-3 double mutants were late flowering under both LD and SD conditions (Figure 2A,B, Supplemental Figure S3), suggesting that HDA6 acts downstream of SIZ1 in the floral promotion pathway. However, genetic analysis demonstrated that HDA6 and SIZ1 may act in an additive manner on the pathway to regulate leaf development, since axe1-5 siz1-3 plants showed more severe curling and serrated leaves compared to WT and the single mutants (Figure 2A, Supplemental Figure S4). A previous study demonstrated that HDA6 is recruited to KNAT1, KNAT2, and KNATM chromatin by the transcription factor AS1, thereby repressing the expression of these genes by downregulating H3ac levels during leaf development [13]. In contrast, SIZ1 plays a role in leaf development by regulating cell division and expansion through SA signaling, which is associated with the expression of XTH, encoding xyloglucan endotransglycosylase/hydrolases [80]. Overexpression of a gene encoding bacterial salicylate hydroxylase $(n a h G)$ in siz1 plants substantially decreases the levels of SA with normal leaf morphology and rosette plant sizes $[30,80]$. Collectively, these findings suggest that HDA6 and SIZ1 may have different roles in leaf development.

In conclusion, our research provides insights regarding the interaction between SIZ1 and HDA6, and their involvement in flowering by regulation of FLC and MAF4 in Arabidopsis. The SUMO E3 Ligase SIZ1 represses HDA6 activity and its binding on target genes to induce $F L C$ and MAF4 expression by increasing the levels of histone $\mathrm{H} 3$ acetylation.

Supplementary Materials: The following are available online at https: / www.mdpi.com/article / 10.3390/cells10113001/s1. Figure S1: Co-IP analysis of the interaction of HDA6 with SIZ1 using transgenic plants. Figure S2: SUMOylation analysis of HDA6 in reconstituted system in Escherichia coli. Figure S3: Flowering phenotypes of WT, axe1-5, siz1-3, axe1-5 siz1-3 plants grown under SD conditions. Figure S4: Leaf phenotypes of 21-day-old WT, axe1-5, siz1-3 and axe1-5 siz1-3 plants under LD. Figure S5: The mRNA levels of HDA6 in 15-day-old Col-0, proHDA6:HDA6-GFP and proHDA6:HDA6-GFP siz1-3 plants using ACTIN2 (A) and UBQ10 (B) as an internal control. Figure S6: The H3ac and H3K9ac levels in axe1-5, siz1-3, axe1-5 siz1-3 plants. Figure S7: Flowering phenotypes of WT, axe1-5, siz1-3, axe1-5 siz1-3, proHDA6:HDA6-GFP and proHDA6:HDA6-GFP siz1-3 plants under LD. Table S1: Primers used in this study.

Author Contributions: Conceptualization, K.W. and S.Y.; data curation, S.G., X.Z., J.W., Y.X., C.Y., Y.H. and S.Y.; formal analysis, S.G., X.Z., J.W., Y.X., F.W. and S.Y.; funding acquisition, S.Y. and X.Z.; investigation, S.G., X.Z., J.W., Y.X., C.Y., Y.H., F.W. and S.Y.; methodology, S.G., X.Z., J.W., Y.X., C.Y. and S.Y.; project administration, K.W. and S.Y.; resources, K.W. and S.Y.; supervision, S.Y. and F.W.; visualization, S.G., J.W., Y.X., C.Y. and Y.H.; writing—original draft, S.G. and X.Z.; writingreview and editing, K.W. and S.Y. All authors have read and agreed to the published version of the manuscript.

Funding: This work was supported partially by the Special Fund for Scientific Innovation StrategyConstruction of High Level Academy of Agriculture Science (R2018PY-QY005 and R2021YJ-QG001), and National Natural Science Foundation of China (31701410 and 31672161). This work was also supported by the Ministry of Science and Technology of Taiwan (108-2311-B-002-013-MY3 and 110-2311-B-002-027) and National Taiwan University (NTU-CC-110L893601).

Institutional Review Board Statement: Not applicable.

Informed Consent Statement: Not applicable.

Data Availability Statement: All material presented here is available upon request: yangsongguang@scbg.ac.cn and kewu@ntu.edu.tw. The supplementary data are attached at the end of this file.

Conflicts of Interest: The authors declare no conflict of interest.

\section{References}

1. Kornberg, R.D. Chromatin structure: A repeating unit of histones and DNA. Science 1974, 184, 868-871. [CrossRef]

2. Luger, K.; Mader, A.W.; Richmond, R.K.; Sargent, D.F.; Richmond, T.J. Crystal structure of the nucleosome core particle at 2.8 angstrom resolution. Nature 1997, 389, 251-260. [CrossRef]

3. Berger, S.L. The complex language of chromatin regulation during transcription. Nature 2007, 447, 407-412. [CrossRef] [PubMed]

4. Patel, D.J.; Wang, Z.X. Readout of Epigenetic Modifications. Annu. Rev. Biochem. 2013, 82, 81-118. [CrossRef] [PubMed] 
5. Kouzarides, T. Chromatin modifications and their function. Cell 2007, 128, 693-705. [CrossRef] [PubMed]

6. Yang, X.J.; Seto, E. HATs and HDACs: From structure, function and regulation to novel strategies for therapy and prevention. Oncogene 2007, 26, 5310-5318. [CrossRef]

7. Simpson, R.T. Structure of chromatin containing extensively acetylated H3 and H4. Cell 1978, 13, 691-699. [CrossRef]

8. Tse, C.; Sera, T.; Wolffe, A.P.; Hansen, J.C. Disruption of higher-order folding by core histone acetylation dramatically enhances transcription of nucleosomal arrays by RNA polymerase III. Mol. Cell Biol. 1998, 18, 4629-4638. [CrossRef]

9. Pandey, R.; Muller, A.; Napoli, C.A.; Selinger, D.A.; Pikaard, C.S.; Richards, E.J.; Bender, J.; Mount, D.W.; Jorgensen, R.A. Analysis of histone acetyltransferase and histone deacetylase families of Arabidopsis thaliana suggests functional diversification of chromatin modification among multicellular eukaryotes. Nucleic Acids Res. 2002, 30, 5036-5055. [CrossRef]

10. Liu, X.C.; Yang, S.G.; Zhao, M.L.; Luo, M.; Yu, C.W.; Chen, C.Y.; Tai, R.; Wu, K.Q. Transcriptional Repression by Histone Deacetylases in Plants. Mol. Plant 2014, 7, 764-772. [CrossRef]

11. Chen, X.S.; Ding, A.B.; Zhong, X.H. Functions and mechanisms of plant histone deacetylases. Sci. China Life Sci. 2020, 63, 206-216. [CrossRef]

12. Jiang, J.; Ding, A.B.; Liu, F.; Zhong, X. Linking signaling pathways to histone acetylation dynamics in plants. J. Exp. Bot. 2020, 71, 5179-5190. [CrossRef] [PubMed]

13. Luo, M.; Yu, C.W.; Chen, F.F.; Zhao, L.M.; Tian, G.; Liu, X.C.; Cui, Y.H.; Yang, J.Y.; Wu, K.Q. Histone Deacetylase HDA6 Is Functionally Associated with AS1 in Repression of KNOX Genes in Arabidopsis. PLoS Genet. 2012, 8, e1003114. [CrossRef] [PubMed]

14. Yu, C.W.; Liu, X.C.; Luo, M.; Chen, C.Y.; Lin, X.D.; Tian, G.; Lu, Q.; Cui, Y.H.; Wu, K.Q. HISTONE DEACETYLASE6 Interacts with FLOWERING LOCUS D and Regulates Flowering in Arabidopsis. Plant Physiol. 2011, 156, 173-184. [CrossRef] [PubMed]

15. Hung, F.Y.; Chen, F.F.; Li, C.L.; Chen, C.; Lai, Y.C.; Chen, J.H.; Cui, Y.H.; Wu, K.Q. The Arabidopsis LDL1/2-HDA6 histone modification complex is functionally associated with CCA1/LHY in regulation of circadian clock genes. Nucleic Acids Res. 2018, 46, 10669-10681. [CrossRef] [PubMed]

16. Hung, F.Y.; Chen, F.F.; Li, C.L.; Chen, C.; Chen, J.H.; Cui, Y.H.; Wu, K.Q. The LDL1/2-HDA6 Histone Modification Complex Interacts With TOC1 and Regulates the Core Circadian Clock Components in Arabidopsis. Front Plant Sci. 2019, 10, 23. [CrossRef]

17. Liu, X.C.; Yu, C.W.; Duan, J.; Luo, M.; Wang, K.C.; Tian, G.; Cui, Y.H.; Wu, K.Q. HDA6 Directly Interacts with DNA Methyltransferase MET1 and Maintains Transposable Element Silencing in Arabidopsis. Plant Physiol. 2012, 158, 119-129. [CrossRef]

18. Yu, C.W.; Tai, R.; Wang, S.C.; Yang, P.; Luo, M.; Yang, S.G.; Cheng, K.; Wang, W.C.; Cheng, Y.S.; Wu, K.Q. HISTONE DEACETYLASE6 Acts in Concert with Histone Methyltransferases SUVH4, SUVH5, and SUVH6 to Regulate Transposon Silencing. Plant Cell. 2017, 29, 1970-1983. [CrossRef]

19. Segre, C.V.; Chiocca, S. Regulating the Regulators: The Post-Translational Code of Class I HDAC1 and HDAC2. J. Biomed. Biotechnol. 2011, 2011, 690848. [CrossRef] [PubMed]

20. Song, Y.; Chi, D.Y.; Yu, P.; Lu, J.J.; Xu, J.R.; Tan, P.P.; Wang, B.; Cui, Y.Y.; Chen, H.Z. Carbocisteine Improves Histone Deacetylase 2 Deacetylation Activity via Regulating Sumoylation of Histone Deacetylase 2 in Human Tracheobronchial Epithelial Cells. Front. Pharmacol. 2019, 10, 166. [CrossRef]

21. Colby, T.; Matthai, A.; Boeckelmann, A.; Stuible, H.P. SUMO-conjugating and SUMO-deconjugating enzymes from Arabidopsis. Plant Physiol. 2006, 142, 318-332. [CrossRef] [PubMed]

22. Saracco, S.A.; Miller, M.J.; Kurepa, J.; Vierstra, R.D. Genetic analysis of SUMOylation in arabidopsis: Conjugation of SUMO1 and SUMO2 to nuclear proteins is essential. Plant Physiol. 2007, 145, 119-134. [CrossRef] [PubMed]

23. Miura, K.; Rus, A.; Sharkhuu, A.; Yokoi, S.; Karthikeyan, A.S.; Raghothama, K.G.; Baek, D.; Koo, Y.D.; Jin, J.B.; Bressan, R.A.; et al. The Arabidopsis SUMO E3 ligase SIZ1 controls phosphate deficiency responses. Proc. Natl. Acad. Sci. USA 2005, 102, 7760-7765. [CrossRef]

24. Cheong, M.S.; Park, H.C.; Hong, M.J.; Lee, J.; Choi, W.; Jin, J.B.; Bohnert, H.J.; Lee, S.Y.; Bressan, R.A.; Yun, D.J. Specific Domain Structures Control Abscisic Acid-, Salicylic Acid-, and Stress-Mediated SIZ1 Phenotypes. Plant Physiol. 2009, 151, $1930-1942$. [CrossRef] [PubMed]

25. Huang, L.X.; Yang, S.G.; Zhang, S.C.; Liu, M.; Lai, J.B.; Qi, Y.L.; Shi, S.F.; Wang, J.X.; Wang, Y.Q.; Xie, Q.; et al. The Arabidopsis SUMO E3 ligase AtMMS21, a homologue of NSE2/MMS21, regulates cell proliferation in the root. Plant J. 2009, 60, 666-678. [CrossRef] [PubMed]

26. Ishida, T.; Fujiwara, S.; Miura, K.; Stacey, N.; Yoshimura, M.; Schneider, K.; Adachi, S.; Minamisawa, K.; Umeda, M.; Sugimoto, K. SUMO E3 Ligase HIGH PLOIDY2 Regulates Endocycle Onset and Meristem Maintenance in Arabidopsis. Plant Cell 2009, 21, 2284-2297. [CrossRef] [PubMed]

27. Tomanov, K.; Zeschmann, A.; Hermkes, R.; Eifler, K.; Ziba, I.; Grieco, M.; Novatchkova, M.; Hofmann, K.; Hesse, H.; Bachmair, A. Arabidopsis PIAL1 and 2 Promote SUMO Chain Formation as E4-Type SUMO Ligases and Are Involved in Stress Responses and Sulfur Metabolism. Plant Cell 2014, 26, 4547-4560. [CrossRef] [PubMed]

28. Elrouby, N. Analysis of Small Ubiquitin-Like Modifier (SUMO) Targets Reflects the Essential Nature of Protein SUMOylation and Provides Insight to Elucidate the Role of SUMO in Plant Development. Plant Physiol. 2015, 169, 1006-1017. [CrossRef] [PubMed]

29. Liu, C.; Yu, H.; Li, L. SUMO modification of LBD30 by SIZ1 regulates secondary cell wall formation in Arabidopsis thaliana. PLoS Genet. 2019, 15, e1007928. [CrossRef] 
30. Jin, J.B.; Jin, Y.H.; Lee, J.; Miura, K.; Yoo, C.Y.; Kim, W.Y.; Van Oosten, M.; Hyun, Y.; Somers, D.E.; Lee, I.; et al. The SUMO E3 ligase, AtSIZ1, regulates flowering by controlling a salicylic acid-mediated floral promotion pathway and through affects on FLC chromatin structure. Plant J. 2008, 53, 530-540. [CrossRef] [PubMed]

31. Son, G.H.; Park, B.S.; Song, J.T.; Seo, H.S. FLC-mediated flowering repression is positively regulated by sumoylation. J. Exp. Bot. 2014, 65, 339-351. [CrossRef] [PubMed]

32. Lin, X.L.; Niu, D.; Hu, Z.L.; Kim, D.H.; Jin, Y.H.; Cai, B.; Liu, P.; Miura, K.; Yun, D.J.; Kim, W.Y.; et al. An Arabidopsis SUMO E3 Ligase, SIZ1, Negatively Regulates Photomorphogenesis by Promoting COP1 Activity. PLoS Genet. 2016, 12. [CrossRef]

33. Sadanandom, A.; Adam, E.; Orosa, B.; Viczian, A.; Klose, C.; Zhang, C.J.; Josse, E.M.; Kozma-Bognar, L.; Nagy, F. SUMOylation of phytochrome-B negatively regulates light-induced signaling in Arabidopsis thaliana. Proc. Natl. Acad. Sci. USA 2015, 112, 11108-11113. [CrossRef] [PubMed]

34. Niu, D.; Lin, X.L.; Kong, X.X.; Qu, G.P.; Cai, B.; Lee, J.; Jin, J.B. SIZ1-Mediated SUMOylation of TPR1 Suppresses Plant Immunity in Arabidopsis. Mol. Plant 2019, 12, 215-228. [CrossRef] [PubMed]

35. Gou, M.Y.; Huang, Q.S.; Qian, W.Q.; Zhang, Z.M.; Jia, Z.H.; Hua, J. Sumoylation E3 Ligase SIZ1 Modulates Plant Immunity Partly through the Immune Receptor Gene SNC1 in Arabidopsis. Mol. Plant Microbe Interact. 2017, 30, 334-342. [CrossRef] [PubMed]

36. Park, B.S.; Song, J.T.; Seo, H.S. Arabidopsis nitrate reductase activity is stimulated by the E3 SUMO ligase AtSIZ1. Nat. Commun. 2011, 2, 1-10. [CrossRef] [PubMed]

37. Castro, P.H.; Verde, N.; Lourenco, T.; Magalhaes, A.P.; Tavares, R.M.; Bejarano, E.R.; Azevedo, H. SIZ1-Dependent PostTranslational Modification by SUMO Modulates Sugar Signaling and Metabolism in Arabidopsis thaliana. Plant Cell Physiol. 2015, 56, 2297-2311. [CrossRef] [PubMed]

38. Miura, K.; Jin, J.B.; Lee, J.; Yoo, C.Y.; Stirm, V.; Miura, T.; Ashworth, E.N.; Bressan, R.A.; Yun, D.J.; Hasegawa, P.M. SIZ1-mediated sumoylation of ICE1 controls CBF3/DREB1A expression and freezing tolerance in Arabidopsis. Plant Cell 2007, 19, 1403-1414 [CrossRef]

39. Rytz, T.C.; Miller, M.J.; McLoughlin, F.; Augustine, R.C.; Marshall, R.S.; Juan, Y.T.; Charng, Y.Y.; Scalf, M.; Smith, L.M.; Vierstra, R.D. SUMOylome Profiling Reveals a Diverse Array of Nuclear Targets Modified by the SUMO Ligase SIZ1 during Heat Stress. Plant Cell 2018, 30, 1077-1099. [CrossRef]

40. Crozet, P.; Margalha, L.; Butowt, R.; Fernandes, N.; Elias, C.A.; Orosa, B.; Tomanov, K.; Teige, M.; Bachmair, A.; Sadanandom, A.; et al SUMOylation represses SnRK1 signaling in Arabidopsis. Plant J. 2016, 85, 120-133. [CrossRef] [PubMed]

41. Zheng, Y.; Schumaker, K.S.; Guo, Y. Sumoylation of transcription factor MYB30 by the small ubiquitin-like modifier E3 ligase SIZ1 mediates abscisic acid response in Arabidopsis thaliana. Proc. Natl. Acad. Sci. USA 2012, 109, 12822-12827. [CrossRef] [PubMed]

42. Miura, K.; Lee, J.; Jin, J.B.; Yoo, C.Y.; Miura, T.; Hasegawa, P.M. Sumoylation of ABI5 by the Arabidopsis SUMO E3 ligase SIZ1 negatively regulates abscisic acid signaling. Proc. Natl. Acad. Sci. USA 2009, 106, 5418-5423. [CrossRef] [PubMed]

43. Miura, K.; Lee, J.; Gong, Q.Q.; Ma, S.S.; Jin, J.B.; Yoo, C.Y.; Miura, T.; Sato, A.; Bohnert, H.J.; Hasegawa, P.M. SIZ1 Regulation of Phosphate Starvation-Induced Root Architecture Remodeling Involves the Control of Auxin Accumulation. Plant Physiol. 2011, 155, 1000-1012. [CrossRef]

44. Kim, S.I.; Park, B.S.; Kim, D.Y.; Yeu, S.Y.; Song, S.I.; Song, J.T.; Seo, H.S. E3 SUMO ligase AtSIZ1 positively regulates SLY1-mediated GA signalling and plant development. Biochem. J. 2015, 469, 299-314. [CrossRef] [PubMed]

45. Zhang, L.; Han, Q.; Xiong, J.; Zheng, T.; Han, J.; Zhou, H.; Lin, H.; Yin, Y.; Zhang, D. Sumoylation of BRI1-EMS-SUPPRESSOR 1 (BES1) by the SUMO E3 Ligase SIZ1 Negatively Regulates Brassinosteroids Signaling in Arabidopsis thaliana. Plant Cell Physiol. 2019, 60, 2282-2292. [CrossRef] [PubMed]

46. Miller, M.J.; Barrett-Wilt, G.A.; Hua, Z.H.; Vierstra, R.D. Proteomic analyses identify a diverse array of nuclear processes affected by small ubiquitin-like modifier conjugation in Arabidopsis. Proc. Natl. Acad. Sci. USA 2010, 107, 16512-16517. [CrossRef]

47. Miller, M.J.; Scalf, M.; Rytz, T.C.; Hubler, S.L.; Smith, L.M.; Vierstra, R.D. Quantitative Proteomics Reveals Factors Regulating RNA Biology as Dynamic Targets of Stress-induced SUMOylation in Arabidopsis. Mol. Cell Proteom. 2013, 12, 449-463. [CrossRef] [PubMed]

48. Clough, S.J.; Bent, A.F. Floral dip: A simplified method for Agrobacterium-mediated transformation of Arabidopsis thaliana. Plant J. 1998, 16, 735-743. [CrossRef] [PubMed]

49. Barth, C.; Jander, G. Arabidopsis myrosinases TGG1 and TGG2 have redundant function in glucosinolate breakdown and insect defense. Plant J. 2006, 46, 549-562. [CrossRef] [PubMed]

50. Yi, Y.; Jack, T. An intragenic suppressor of the Arabidopsis floral organ identity mutant apetala3-1 functions by suppressing defects in splicing. Plant Cell. 1998, 10, 1465-1477. [CrossRef] [PubMed]

51. Gietz, R.D.; Woods, R.A. Transformation of yeast by lithium acetate/single-stranded carrier DNA/polyethylene glycol method. Methods Enzymol. 2002, 350, 87-96. [CrossRef] [PubMed]

52. Lu, Q.; Tang, X.; Tian, G.; Wang, F.; Liu, K.; Nguyen, V.; Kohalmi, S.E.; Keller, W.A.; Tsang, E.W.; Harada, J.J. Arabidopsis homolog of the yeast TREX-2 mRNA export complex: Components and anchoring nucleoporin. Plant J. 2010, 61, 259-270. [CrossRef] [PubMed]

53. Yoo, S.-D.; Cho, Y.-H.; Sheen, J. Arabidopsis mesophyll protoplasts: A versatile cell system for transient gene expression analysis. Nat. Protoc. 2007, 2, 1565-1572. [CrossRef] [PubMed]

54. Zhao, Z.; Li, T.; Peng, X.; Wu, K.; Yang, S. Identification and Characterization of Tomato SWI3-Like Proteins: Overexpression of SISWIC Increases the Leaf Size in Transgenic Arabidopsis. Int. J. Mol. Sci. 2019, 20, 5121. [CrossRef] [PubMed] 
55. Jackson, J.P.; Johnson, L.; Jasencakova, Z.; Zhang, X.; PerezBurgos, L.; Singh, P.B.; Cheng, X.D.; Schubert, I.; Jenuwein, T.; Jacobsen, S.E. Dimethylation of histone H3 lysine 9 is a critical mark for DNA methylation and gene silencing in Arabidopsis thaliana. Chromosoma 2004, 112, 308-315. [CrossRef] [PubMed]

56. Gendrel, A.V.; Lippman, Z.; Martienssen, R.; Colot, V. Profiling histone modification patterns in plants using genomic tiling microarrays. Nat. Methods. 2005, 2, 213-218. [CrossRef] [PubMed]

57. Zhao, M.L.; Yang, S.G.; Chen, C.Y.; Li, C.L.; Shan, W.; Lu, W.J.; Cui, Y.H.; Liu, X.C.; Wu, K.Q. Arabidopsis BREVIPEDICELLUS Interacts with the SWI2/SNF2 Chromatin Remodeling ATPase BRAHMA to Regulate KNAT2 and KNAT6 Expression in Control of Inflorescence Architecture. PLoS Genet. 2015, 11, e1005125. [CrossRef]

58. Johnson, L.M.; Cao, X.F.; Jacobsen, S.E. Interplay between two epigenetic marks: DNA methylation and histone H3 lysine 9 methylation. Curr. Biol. 2002, 12, 1360-1367. [CrossRef]

59. Okada, S.; Nagabuchi, M.; Takamura, Y.; Nakagawa, T.; Shinmyozu, K.; Nakayama, J.; Tanaka, K. Reconstitution of Arabidopsis thaliana SUMO Pathways in E-coli: Functional Evaluation of SUMO Machinery Proteins and Mapping of SUMOylation Sites by Mass Spectrometry. Plant Cell Physiol. 2009, 50, 1049-1061. [CrossRef] [PubMed]

60. Zhang, J.; Lai, J.; Wang, F.; Yang, S.; He, Z.; Jiang, J.; Li, Q.; Wu, Q.; Liu, Y.; Yu, M.; et al. A SUMO Ligase AtMMS21 Regulates the Stability of the Chromatin Remodeler BRAHMA in Root Development. Plant Physiol. 2017, 173, 1574-1582. [CrossRef] [PubMed]

61. Budhiraja, R.; Hermkes, R.; Muller, S.; Schmidt, R.; Colby, T.; Panigrahi, K.; Coupland, G.; Bachmair, A. Substrates Related to Chromatin and to RNA-Dependent Processes Are Modified by Arabidopsis SUMO Isoforms That Differ in a Conserved Residue with Influence on Desumoylation. Plant Physiol. 2009, 149, 1529-1540. [CrossRef] [PubMed]

62. Engelsberger, W.R.; Schulze, W.X. Nitrate and ammonium lead to distinct global dynamic phosphorylation patterns when resupplied to nitrogen-starved Arabidopsis seedlings. Plant J. 2012, 69, 978-995. [CrossRef] [PubMed]

63. Zhao, Q.; Xie, Y.; Zheng, Y.; Jiang, S.; Liu, W.; Mu, W.; Liu, Z.; Zhao, Y.; Xue, Y.; Ren, J. GPS-SUMO: A tool for the prediction of sumoylation sites and SUMO-interaction motifs. Nucleic Acids Res. 2014, 42, W325-W330. [CrossRef] [PubMed]

64. Yang, J.; Yuan, L.; Yen, M.R.; Zheng, F.; Ji, R.; Peng, T.; Gu, D.; Yang, S.; Cui, Y.; Chen, P.Y.; et al. SWI3B and HDA6 interact and are required for transposon silencing in Arabidopsis. Plant J. 2020, 102, 809-822. [CrossRef] [PubMed]

65. Gu, D.C.; Chen, C.Y.; Zhao, M.L.; Zhao, L.M.; Duan, X.W.; Duan, J.; Wu, K.Q.; Liu, X.C. Identification of HDA15-PIF1 as a key repression module directing the transcriptional network of seed germination in the dark. Nucleic Acids Res. 2017, 45, 7137-7150. [CrossRef] [PubMed]

66. Zhao, L.M.; Peng, T.; Chen, C.Y.; Ji, R.J.; Gu, D.C.; Li, T.T.; Zhang, D.D.; Tu, Y.S.; Wu, K.Q.; Liu, X.C. HY5 Interacts with the Histone Deacetylase HDA15 to Repress Hypocotyl Cell Elongation in Photomorphogenesis. Plant Physiol. 2019, 180, 1450-1466. [CrossRef] [PubMed]

67. Khan, I.U.; Ali, A.; Khan, H.A.; Baek, D.; Park, J.; Lim, C.J.; Zareen, S.; Jan, M.; Lee, S.Y.; Pardo, J.M.; et al. PWR/HDA9/ ABI4 Complex Epigenetically Regulates ABA Dependent Drought Stress Tolerance in Arabidopsis. Front Plant Sci. 2020, 11, 623. [CrossRef]

68. Bahl, S.; Seto, E. Regulation of histone deacetylase activities and functions by phosphorylation and its physiological relevance. Cell Mol. Life Sci. 2021, 78, 427-445. [CrossRef]

69. David, G.; Neptune, M.A.; DePinho, R.A. SUMO-1 modification of histone deacetylase 1 (HDAC1) modulates its biological activities. J. Biol. Chem. 2002, 277, 23658-23663. [CrossRef] [PubMed]

70. Brandl, A.; Wagner, T.; Uhlig, K.M.; Knauer, S.K.; Stauber, R.H.; Melchior, F.; Schneider, G.; Heinzel, T.; Kramer, O.H. Dynamically regulated sumoylation of HDAC2 controls p53 deacetylation and restricts apoptosis following genotoxic stress. J. Mol. Cell Biol. 2012, 4, 284-293. [CrossRef] [PubMed]

71. Wagner, T.; Kiweler, N.; Wolff, K.; Knauer, S.K.; Brandl, A.; Hemmerich, P.; Dannenberg, J.H.; Heinzel, T.; Schneider, G.; Krämer, O.H. Sumoylation of HDAC2 promotes NF-kB-dependent gene expression. Oncotarget 2015, 6, 7123. [CrossRef] [PubMed]

72. Wils, C.R.; Kaufmann, K. Gene-regulatory networks controlling inflorescence and flower development in Arabidopsis thaliana. Biochim. Biophys. Acta Gene Regul. Mech. 2017, 1860, 95-105. [CrossRef]

73. Farrona, S.; Hurtado, L.; March-Díaz, R.; Schmitz, R.J.; Florencio, F.J.; Turck, F.; Amasino, R.M.; Reyes, J.C. Brahma is required for proper expression of the floral repressor FLC in Arabidopsis. PLoS ONE 2011, 6, e17997. [CrossRef] [PubMed]

74. Hurtado, L.; Farrona, S.; Reyes, J.C. The putative SWI/SNF complex subunit BRAHMA activates flower homeotic genes in Arabidopsisthaliana. Plant Mol. Biol. 2006, 62, 291-304. [CrossRef] [PubMed]

75. Li, D.; Liu, C.; Shen, L.; Wu, Y.; Chen, H.; Robertson, M.; Helliwell, C.A.; Ito, T.; Meyerowitz, E.; Yu, H. A repressor complex governs the integration of flowering signals in Arabidopsis. Dev. Cell. 2008, 15, 110-120. [CrossRef]

76. Fujiwara, S.; Oda, A.; Yoshida, R.; Niinuma, K.; Miyata, K.; Tomozoe, Y.; Tajima, T.; Nakagawa, M.; Hayashi, K.; Coupland, G. Circadian clock proteins LHY and CCA1 regulate SVP protein accumulation to control flowering in Arabidopsis. Plant Cell 2008, 20, 2960-2971. [CrossRef]

77. Gu, X.; Le, C.; Wang, Y.; Li, Z.; Jiang, D.; Wang, Y.; He, Y. Arabidopsis FLC clade members form flowering-repressor complexes coordinating responses to endogenous and environmental cues. Nat. Commun. 2013, 4, 1-10. [CrossRef]

78. Miura, K.; Renhu, N.; Suzaki, T. The PHD finger of Arabidopsis SIZ1 recognizes trimethylated histone H3K4 mediating SIZ1 function and abiotic stress response. Commun. Biol. 2020, 3, 1-10. [CrossRef] 
79. Shi, X.; Hong, T.; Walter, K.L.; Ewalt, M.; Michishita, E.; Hung, T.; Carney, D.; Pena, P.; Lan, F.; Kaadige, M.R. ING2 PHD domain links histone H3 lysine 4 methylation to active gene repression. Nature 2006, 442, 96-99. [CrossRef]

80. Miura, K.; Lee, J.; Miura, T.; Hasegawa, P.M. SIZ1 Controls Cell Growth and Plant Development in Arabidopsis through Salicylic Acid. Plant Cell Physiol. 2010, 51, 103-113. [CrossRef] [PubMed] 